\title{
Efficacy and side effects of antibiotics in the treatment of acute rhinosinusitis: a systematic review*
}

\author{
Weirong Joshua Sng'1, De-Yun Wang² \\ 1 House Officer, Yong Loo Lin School of Medicine. National University of Singapore, Singapore \\ 2 Department of Otolaryngology, Yong Loo Lin School of Medicine. National University of Singapore, Singapore
}

Rhinology 53: 3-9, 2015

DOl:10.4193/Rhino13.225

*Received for publication:

December 29, 2013

Accepted: September 10, 2014

\begin{abstract}
Background: Acute rhinosinusitis (ARS) is one of the most common diagnoses for which an antibiotic is prescribed. Although the usage of antibiotics in the treatment of mild, moderate or uncomplicated ARS is not recommended by most international guidelines, overuse of antibiotics is still an alarming problem among patients and healthcare practitioners. We thus sought to review the evidence available through a systematic review of the existing literature on antibiotic usage in ARS.
\end{abstract}

Methodology: A search of the PubMed database was conducted for studies on antibiotic and placebo usage in the treatment of ARS.

Results: A total of 31 random control trials (RCT) reporting the clinical efficacy of treating ARS and side effects of using cefuroxime axetil, telithromycin, amoxicillin/potassium clavulanate, levofloxacin, moxifloxacin and clarithromycin were included in the review. Among them, 9 studies were performed double-blinded with placebo controls. The results showed that while antibiotics are more efficacious than placebos in the treatment of ARS, the risks of potential side effects need to be weighed against the potential benefit that antibiotics give to the patient. This is especially pertinent as usage of the placebo has shown to be almost as efficacious as using the antibiotic therapy, and also much safer.

Conclusion: The usage of antibiotics in ARS is widespread and there seems to be only slight added benefit in the usage of antibiotics over placebo in the treatment of ARS. Hence, larger scale studies should be done in the future to confirm the results of these studies.

Key words: systemic review, acute rhinosinusitis, efficacy, side effect, antibiotics, placebo effect

\section{Introduction}

Acute rhinosinusitis (ARS) is defined as a sudden onset of two or more symptoms, including one of either two key symptoms of nasal blockage/obstruction/congestion or nasal discharge, and facial pain/pressure and reduction or loss of smell for less than 12 weeks ${ }^{(1)}$. In the European Position Paper on Rhinosinusitis and Nasal polyps ${ }^{(2)}$, ARS has been further classified into viral ARS (common cold) and post-viral ARS, where a small percentage of the patients with post-viral ARS will have bacterial ARS (2). It is a common and significant health problem worldwide, with prevalence rates varying from 6-15\% depending on the study parameters, and is one of the top reasons for a visit to the primary care physician ${ }^{(2)}$.

Antibiotic therapy has long been used in the treatment of ARS, and ARS accounted for $9 \%$ and $21 \%$ of all paediatric and adult antibiotic prescriptions, respectively, in the USA in 2002

(3). According to the National Ambulatory Medical Care Survey (NAMCS) data, rhinosinusitis is the fifth most common diagnosis for which an antibiotic is prescribed ${ }^{(2)}$. On the other hand, the global threat posed by emerging resistant microorganisms has become an international health issue, directly resulting from the careless abuse of antibiotics. The overuse of antibiotics has been reported in some European countries ${ }^{(4)}$ to have directly resulted 
in an increased prevalence of antimicrobial resistance in Europe

(5). This phenomenon has also been confirmed by a recent survey on the management of ARS among Asian physicians ${ }^{(6)}$. Hence, appropriate physician education promoting better understanding of the nature of ARS and evidenced-based treatment options will not only improve treatment outcomes, but also play an important role in combating the emerging healthcare issue resulting from the rising global antimicrobial resistance.

It has been stated clearly in a position paper (2001) and other studies that ARS resolves without antibiotic treatment in most cases ${ }^{(7-9)}$. Symptomatic treatment and reassurance is the preferred initial management strategy for patients with mild symptoms. Antibiotic therapy should be reserved for patients with high fever or severe (unilateral) facial pain ${ }^{(2)}$. Consensus in the management of ARS among GPs and different specialties who commonly treat ARS is very important. In the literature, multiple studies have been done to demonstrate the efficacy and safety profile of the various antibiotics used in the treatment of ARS, but there has been no systematic review done comparing the efficacy and safety of the different antibiotics. We thus sought to review the evidence available through a systematic review of the existing literature on antibiotic usage in ARS.

The aim of the study was to study the usage of common antibiotics used in the treatment of ARS, thus providing practitioners an idea of the efficacy and safety profile of these commonly used antibiotics.

\section{Materials and methods}

We performed a literature search of randomised controlled trials (RCT) to compare the efficacy and safety profile of commonly used antibiotics in the treatment of ARS (Scheme 1). To find the relevant studies, we searched the PubMed database. The following search terms were used "(acute sinusitis OR acute rhinosinusitis OR acute sinus infection) AND (antibiotics OR antibacterial agents OR drug therapy) AND randomized controlled". No limits were set for the performed search.

All retrieved articles were screened based on the title as well as the abstract. Full-text papers of relevant studies were then obtained for further evaluation. Only RCT studies that were published in English were evaluated and included. The diagnosis and evaluation of cure of ARS was required to be by clinical and/ or radiological $(n=8)$ criteria and/or bacteriological criteria $(n=$ 4) in patients with symptoms of ARS, and only antibiotics with at least 5 independent studies or more were included in our study. Clinical symptoms used by these studies to diagnose ARS included major criteria such as frontal or maxillary pain/tightness, purulent nasal discharge, or pus seen on nasoendoscopy and minor criteria such as sore throat, cough, fever, change in

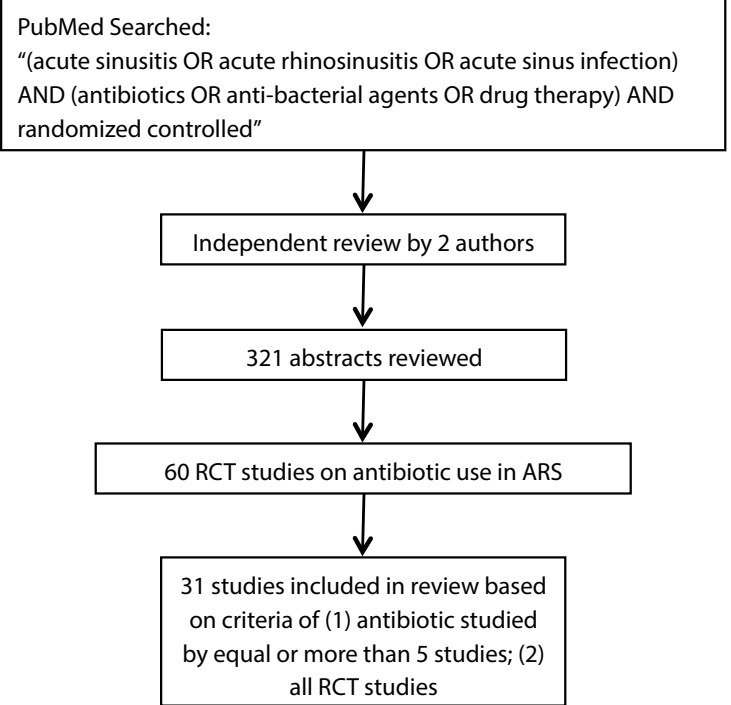

Scheme 1. Flow chart.

perception of smell, halitosis or earache. These studies also incorporated these clinical symptoms into a written questionnaire, a verbal questionnaire or a phone questionnaire at the test-ofcure visits, which, together with physical and/or endoscopic examination looking for signs such as postnasal drip, facial tenderness over the sinuses, and pus seen on rhinoendoscopy was used as clinical outcome measures to determine cure. Data from these selected articles were then extracted and tabulated, focusing on the inclusion and exclusion criteria, number of patients, efficacy of the antibiotic treatment regimen (outcomes), side effects reported, and the antibiotic treatment regimen itself (dose and duration). Studies that looked at chronic rhinosinusitis or other lower respiratory tract infections, or other modalities of treatment other than antibiotics were excluded from our study.

\section{Results}

A total of 321 abstracts were found using the above search criteria. Of these 321 abstracts, a total of 31 studies satisfied the criteria for this review, and the antibiotics reviewed in this paper include cefuroxime axetil, telithromycin, amoxicillin/potassium clavulanate, levofloxacin, moxifloxacin and clarithromycin. Among them, nine studies were performed double-blinded with placebo controls. All studies used clinical outcomes to evaluate efficacy of treatment, and a small number of studies had secondary endpoints using radiological or bacteriological measures. Studies which had secondary endpoints have been indicated in Figures 1-8. The majority of studies had study endpoints at 1014 days as well as 28-42 days post-treatment to look for cure.

\section{Cefuroxime axetil (Figure 1)}

Studies focusing on cefuroxime axetil found that the efficacy of cefuroxime axetil at $250 \mathrm{mg}$ twice daily has an efficacy above 
Table 1. Combined table of Antibiotics $(n=41)$.

\begin{tabular}{|c|c|c|c|c|c|c|c|}
\hline $\begin{array}{l}\text { Number of } \\
\text { Studies }\end{array}$ & $\begin{array}{l}\text { No. of study } \\
\text { patients }\end{array}$ & Drug & Dose/Duration & $\begin{array}{l}\text { Primary } \\
\text { Outcomes }\end{array}$ & $\begin{array}{c}\text { Efficacy \% } \\
\text { Median (range) }\end{array}$ & $\begin{array}{l}\text { Side-Effects \% } \\
\text { (minor) }\end{array}$ & $\begin{array}{l}\text { Level of } \\
\text { Evidence }\end{array}$ \\
\hline 10 & 1888 & $\begin{array}{l}\text { Cefuroxime } \\
\text { axetil }\end{array}$ & $\begin{array}{l}125-250 \mathrm{mg} \\
\mathrm{BD} / 5-10 \text { days }\end{array}$ & $\begin{array}{l}\text { Clinical cure } \\
\text { rates at test-of- } \\
\text { cure visit }\end{array}$ & $85(63-91.1)$ & $8.1-34.2$ & 1B \\
\hline 7 & 1563 & Telithromycin & $\begin{array}{l}800 \mathrm{mg} \mathrm{OD} / 5-10 \\
\text { days }\end{array}$ & $\begin{array}{l}\text { Clinical cure } \\
\text { rates at test-of- } \\
\text { cure visit }\end{array}$ & $80.9(72.9-91.1)$ & $21.3-46.9$ & 1B \\
\hline 7 & 973 & $\begin{array}{l}\text { Amoxicillin/ } \\
\text { potassium clavu- } \\
\text { lanate }\end{array}$ & $\begin{array}{l}500-875 \mathrm{~g} / 125 \\
\mathrm{mg} \text { for } 6-14 \text { days }\end{array}$ & $\begin{array}{l}\text { Clinical cure } \\
\text { rates at test-of- } \\
\text { cure visit }\end{array}$ & $77.4(50-93)$ & $17-51.1$ & 1B \\
\hline 6 & 1050 & Levofloxacin & $\begin{array}{l}500-750 \mathrm{mg} \\
\mathrm{OD}, 5-10 \text { days }\end{array}$ & $\begin{array}{l}\text { Clinical success, } \\
\text { resolution of } \\
>\text { or }=3 \text { ARS } \\
\text { symptoms }\end{array}$ & $91.4(23.4-93.9)$ & $15.3-39.8$ & 1B \\
\hline 5 & 937 & Moxifloxacin & $\begin{array}{l}400 \mathrm{mg} \text { OD, 5-10 } \\
\text { days }\end{array}$ & $\begin{array}{l}\text { Clinical cure } \\
\text { rates at test-of- } \\
\text { cure visit }\end{array}$ & 86 & $16.9-38.2$ & 1B \\
\hline 5 & 835 & Clarithromycin & $\begin{array}{l}500 \mathrm{mg} \mathrm{BD} / 10- \\
14 \text { days }\end{array}$ & $\begin{array}{l}\text { Clinical cure } \\
\text { rates at test-of- } \\
\text { cure visit }\end{array}$ & 85 (79-93.5) & $28-48.4$ & 1B \\
\hline
\end{tabular}

BD: Twice daily, OD: Once daily.

$75 \%(n=9)^{(10-18)}$, which is higher than the efficacy at $125 \mathrm{mg}$ twice daily with an efficacy of $63 \%(n=1)^{(19)}$. The occurrence of side effects in the dosing regimen of $125 \mathrm{mg}$ twice daily was also significantly lower, with only $5.4 \%$ of patients reporting side effects, while patients using a dosing regimen of $250 \mathrm{mg}$ twice daily reported adverse effects ranging from $8.1 \%$ to $34.2 \%$, with the median percentage of adverse effects being reported at $22.6 \%$. The most commonly reported side effects included diarrhoea, nausea, dizziness and vomiting.

\section{Telithromycin (Figure 2)}

The efficacy of telithromycin in treating ARS ranged from $72.9 \%$ to $91.1 \%$. All studies reviewed used a dose of $800 \mathrm{mg}$ OD. Most studies had a dosing regimen that lasted for 5 days $(n=5)^{(11-13,}$ ${ }^{20-22)}$ while the rest had a dosing regimen that lasted for 10 days $(n=2)^{(21,22)}$. There was no significant difference in the efficacy of using telithromycin $800 \mathrm{mg}$ OD for 10 days over 5 days (10 days: 75.3\% - 91\%; 5 days: $72.9 \%$ - 91.1\%). The objective benchmark for evaluating efficacy of telithromycin treatment was clinical cure rates at test-of-cure visit. Minor side effects were reported anywhere from $21.3 \%$ to $46.9 \%$ for the 10 days treatment regimen, and $30.1 \%$ to $42.2 \%$ for the 5 days treatment (not significant). There were no major side effects observed.
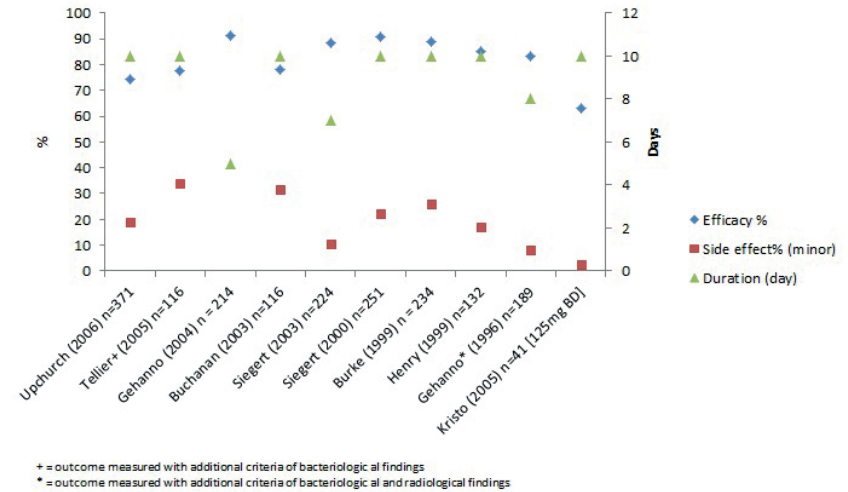

Figure 1. Comparing the dose and duration versus the clinical efficacyside effects of cefuroxime axetil (without title).

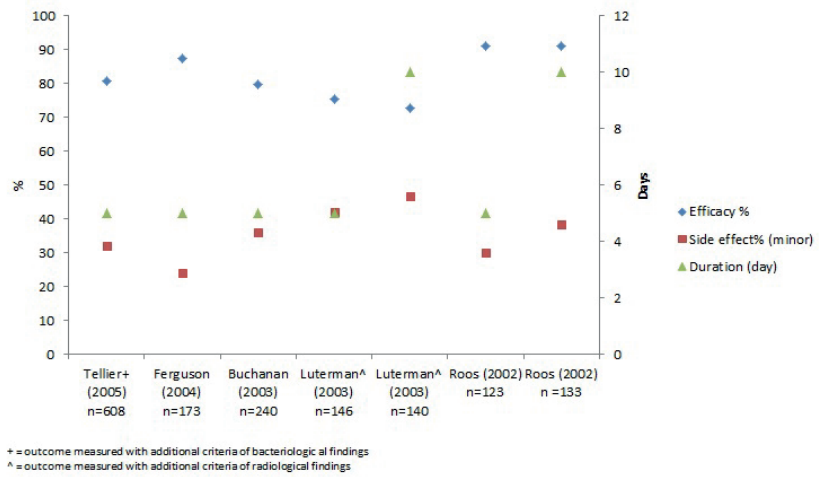

Figure 2. Comparing the dose and duration versus the clinical efficacyside effects of telithromycin (without title). 


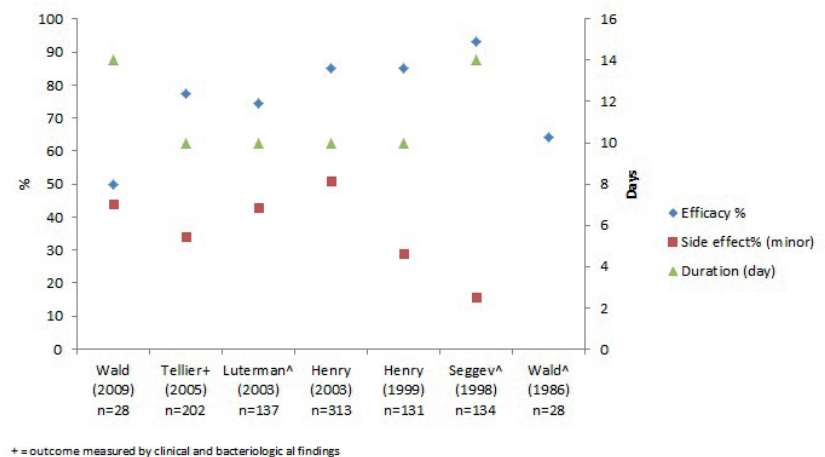

Figure 3. Comparing the dose and duration versus the clinical efficacyside effects of amoxicillin and potassium clavulanate (without title).

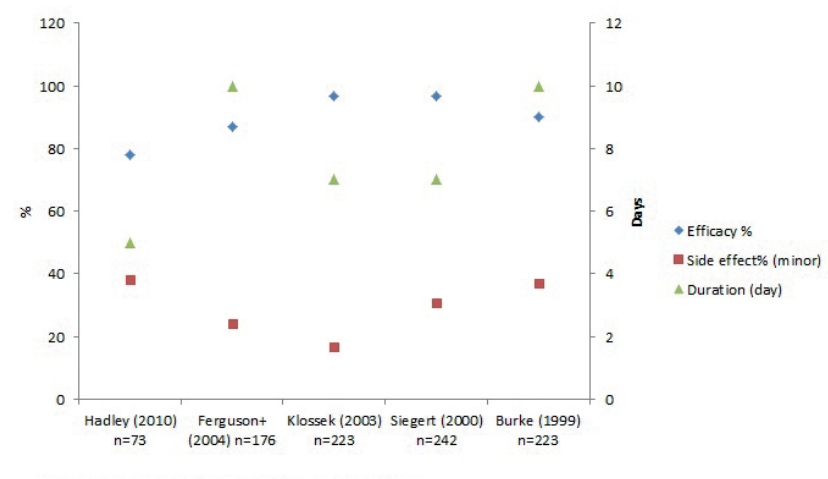

Figure 5. Comparing the dose and duration versus the clinical efficacyside effects of moxifloxacin (without title).

Amoxicillin/potassium clavulanate (Figure 3)

The efficacy of amoxicillin/potassium clavulanate ranged from $50 \%$ to $93 \%$. All studies ${ }^{(11,17,21,23-25)}$ used a dosing regimen of $500 / 125 \mathrm{mg}$ thrice a day for 10 to 14 days. Most studies reported quite a high incidence of minor adverse effects, with 3 studies reporting a side effect rate of more than $40 \%(21,23,24)$.

\section{Levofloxacin (Figure 4)}

With regards to levofloxacin, 5 studies reported efficacies over $86 \%$, but another 1 study reported an efficacy of only $23.4 \%{ }^{(26)}$. Most studies were made on a dosing regimen of $500 \mathrm{mg}$ once daily for 10 days $(n=5)^{(26-30)}$, but 1 study used a dosing regimen of $500 \mathrm{mg}$ once daily for 5 days ${ }^{(27)}$. There was no apparent difference in efficacy between a 5 days and 10 days dosing regimen. Most studies on levofloxacin showed minor side effect occurrences to be less than $22.5 \%(n=4)^{(26,28-30)}$, although 2 studies showed it to be around $40 \%{ }^{(27)}$. No major side effects were otherwise observed.

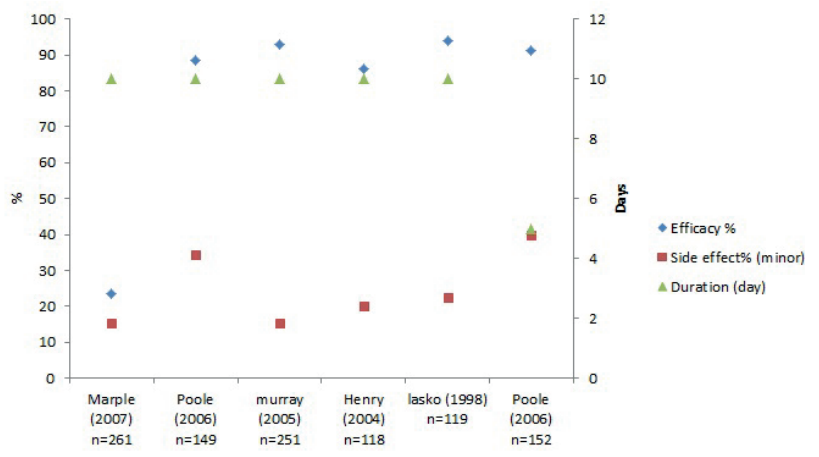

Figure 4. Comparing the dose and duration versus the clinical efficacyside effects of levofloxacin (without title).

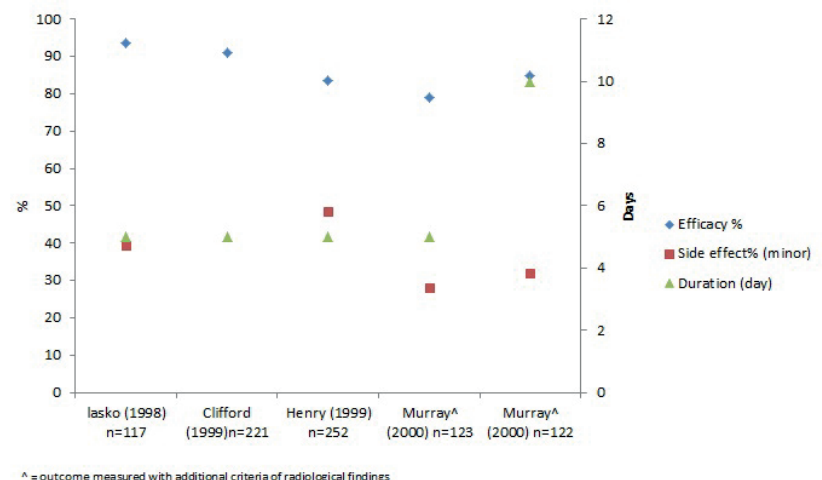

Figure 6. Comparing the dose and duration versus the clinical efficacyside effects of clarithromycin (without title).

\section{Moxifloxacin (Figure 5)}

The majority of studies performed on moxifloxacin showed an efficacy close to or above $90 \%{ }^{(14,16,20,31)}$. All studies were carried out using a dosing regimen of $400 \mathrm{mg}$ one daily, given from a period of 5 to 10 days. The minor side effect profile of moxifloxacin ranged from $24.3 \%$ to $38.2 \%$ and no major side effects were observed.

\section{Clarithromycin (Figure 6)}

The efficacy of clarithromycin was relatively high, with a range from $79 \%$ to $93.5 \%{ }^{(17,30,32,33)}$. All studies were performed with a total of $1000 \mathrm{mg}$ given per day, for either 5 or 10 days, and no significant increase in efficacy or duration was noted with the 10 days regimen compared to the 5 days one.

\section{Placebo effects (Figure 7 and 8)}

The efficacy and side effect profile of placebos were generally lower than that of compared antibiotics, and the antibiotics studied in the 9 studies comparing efficacy and side effects 


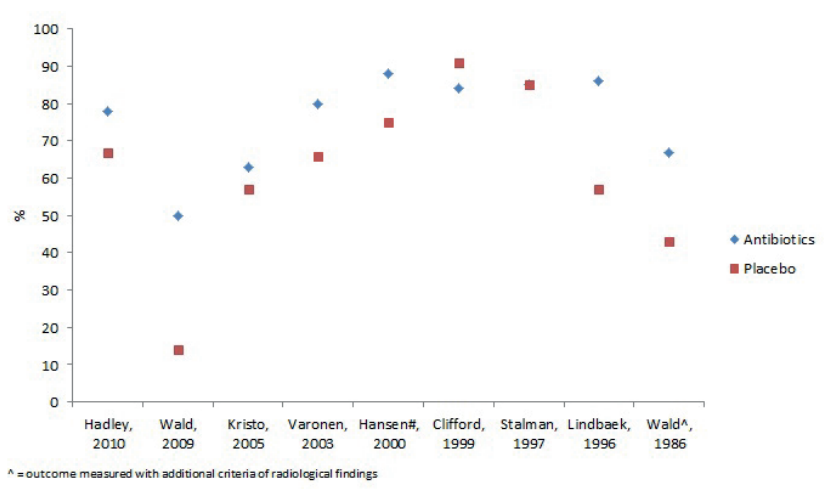

Figure 7. Comparing the clinical efficacy between antibiotics and placebo (without title).

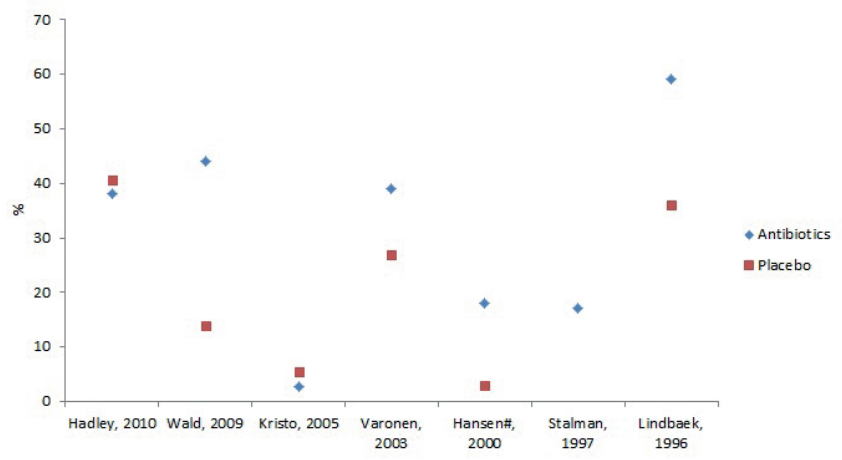

Figure 8. Comparing the side effects between antibiotics and placebo (without title). of antibiotics had an efficacy ranging from $50-88 \%$ (19,24,32,34-39), as compared to an efficacy of $14-91 \%{ }^{(19,24,32,34-39)}$ for placebos compared in the studies. A similar comparison of the side effects showed that $2.7-59 \%^{(1,9,24,35-39)}$ of patients on antibiotics reported side effects, while $0-40.7 \%{ }^{(19,24,35-39)}$ of patients on placebos showed adverse effects.

\section{Discussion}

In general, studies carried out to determine the efficacy of antibiotics in treating ARS have shown that they are effective treatments, with most antibiotics having an efficacy well above $80 \%$. However, many of these studies also reported a high degree of minor side effects, with some antibiotics having up to a $40 \%$ incidence of side effects ${ }^{(39)}$. The most common side effects reported were gastrointestinal related and included nausea, vomiting, diarrhoea and abdominal pain.

With the exception of 1 study, the efficacy of levofloxacin seems to be the highest. The study that showed an efficacy of only $23 \%{ }^{(26)}$ assessed resolution of symptoms at the on-treatment visit (day 3-5), which was significantly earlier than the other studies that assessed test-of-cure at a later date. Resolution of symptoms at day 3-5 would thus be significantly lower than assessment at day 21 or later due to various factors such as the natural course of ARS. Within the same antibiotic, studies which showed a lower incidence of side effects generally only included side effects that were possibly related to the treatment, while studies which reported higher incidences ( $>40 \%$ ) tended to include all side effects, regardless of the relation to the antibiotic treatment. Poole et al. ${ }^{(27)}$ found a significantly higher side effect profile of levofloxacin $500 \mathrm{mg}$ and $750 \mathrm{mg}$ as compared to results from other studies (34.5\% and $39.8 \%$, respectively). This was because of the inclusion of treatment-emergent adverse events from the beginning of therapy on day 1 till the end of the study on day 24 , whether related to the treatment or not, and could have included a significant percentage of treatment unrelated adverse events.

Levofloxacin has been shown to have a high efficacy in the treatment of ARS with a high safety profile, and side effects being minor and predominantly gastrointestinal in nature. More research should be done to assess its viability as a first line antibiotic of choice in the treatment of ARS. Conversely, while the efficacy of clarithromycin (79\% - 91\%) and telithromycin $(72.9 \%-91.9 \%)$ is high, the incidence of side effects reported in the various studies done has also been shown to be high, with an incidence of $28 \%-48.4 \%^{(17,28,30)}$ and $24.1 \%-46.9 \%{ }^{(11,13,20-22)}$, respectively. Clarithromycin and telithromycin should be used judiciously and their efficacy needs to be balanced against the common side effects. An interesting point to note is that studies on telithromycin reported no significant difference between efficacy and side effects in the use of telithromycin $800 \mathrm{mg}$ OD for 5 days or 10 days, suggesting that there is no added benefit for a 10 day regimen over a 5 day one.

For amoxicillin/potassium clavulanate, the efficacy ranges from $50 \%$ to $93 \%{ }^{(11,21,23-25,34)}$. One reason for the large range could be due to the 2 studies by Wald et al. ${ }^{(24,34)}$, which had small sample sizes of 28 patients in each study. The low efficacy of amoxicillin/ potassium clavulanate found in these studies could possibly be thus in part due to random error, and not an accurate measure of the efficacy of the antibiotic used. The efficacy of amoxicillin/potassium clavulanate found in the other 5 studies ranged from $74.5 \%-93 \%^{(11,17,21,23,25)}$, suggesting that the true efficacy of amoxicillin/potassium clavulanate is probably closer to $80 \%$. In general, between studies, we note that there is a big variation of efficacy and side effects even just within the same drug, and in the future we need more standardized studies to be able to have better evidence on the efficacy and side effects of various drugs used in the treatment of ARS. 
With reference to Figure 7 and 8, the antibiotics studied in the 9 studies comparing efficacy and side effects of antibiotics versus placebo showed that antibiotics are generally effective in treating ARS. This is true across the different antibiotics used in the treatment of ARS, most of which are commonly used in general practice for the treatment of ARS. However, the efficacy of placebos was found to be high in the studies as well, suggesting that there is a significant placebo effect present in the use of antibiotics to treat ARS. Some authors ${ }^{(36)}$ have suggested that this is due in large part to the natural course of ARS, which tends to resolve clinically a few days after onset of symptoms. Studies also found that the usage of placebos generally causes fewer side effects than that of antibiotics (which is to be expected), although Hadley et al. ${ }^{(39)}$ and Kristo et al. ${ }^{(19)}$ reported that the placebo group of patients actually experienced slightly more side effects (2-3\%) than the antibiotic group of patients.

It can thus be seen that while antibiotics are more efficacious than placebos in the treatment of ARS, the risks of potential side effects need to be weighed against the potential benefit that antibiotics give to the patient. This is especially pertinent as usage of the placebo has shown to be almost as efficacious as using the antibiotic therapy, and also much safer. As there are only 9 studies performed thus far to compare antibiotics with placebos, and antibiotics used in the different studies are not the same, larger scale studies should be done in the future to confirm the results of these studies. In addition, it is important to note that both the Dutch study ${ }^{\left({ }^{(0)}\right)}$ and the study by Babar-Craig (41), which was based on returned questionnaires by members of the British Rhinology Society and probably underestimated the incidence of complications, showed that prescription of antibiotics for ARS does not prevent the occurrence of complications. These facts, together with the risk of antibiotic resistance and of masking intracranial complications argue strongly against the routine use of antibiotics in ARS (2).

There are some limitations of this review that the diagnosis of ARS is difficult to standardize, and a good number of papers ( $n$ $=22$ ) reviewed were studied before the 2005 European position paper on rhinosinusitis and nasal polyps ${ }^{(42)}$ was published, suggesting that the diagnosis of ARS should be made based on duration of symptoms. We note, however, that the majority of these 22 studies done before 2005 used similar criteria as the one suggested in the 2005 EPOS guidelines ${ }^{(42)}$. We also recognize that due to the stringent inclusion criteria we have used, there are potentially other antibiotics that are used in the treatment of ARS and have been studied, which may have been omitted in this paper.

\section{Conclusion}

The use of antibiotics in the treatment of ARS is widespread. However, clinical studies have found that while antibiotics are efficacious in treating ARS, there is a large placebo effect present as well, which may be due in part to the natural course of the disease. The side effects of antibiotics to treat ARS must be balanced against the therapeutic effect of antibiotics. Larger double-blind placebo controlled studies should be performed to effectively evaluate the true efficacy of antibiotics in the treatment of ARS.

\section{Authorship contribution}

Both authors have contributed to the study design, data search and analysis, and writing of the manuscript.

\section{Conflicts of Interest}

No conflicts of interest exists for each author involved in this manuscript.

\section{References}

1. Fokkens W, Lund V, Mullol J, European Position Paper on R, Nasal Polyps g European position paper on rhinosinusitis and nasal polyps 2007. Rhinology Supplement. 2007 (20): 1-136.

2. Fokkens WJ, Lund VJ, Mullol J, et al. EPOS 2012: European position paper on rhinosinusitis and nasal polyps 2012. A summary for otorhinolaryngologists. Rhinology. 2012 50: 1-12.

3. Anon JB, Jacobs MR, Poole MD, et al. Antimicrobial treatment guidelines for acute bacterial rhinosinusitis. Otolaryngol Head Neck Surg. 2004; 130 (1 Suppl): 1-45.

4. Cars O, Molstad S, Melander A. Variation in antibiotic use in the European Union. Lancet. 2001. 9; 357: 1851-1853.

5. Goossens $H$, Ferech M, Vander Stichele R, Elseviers M, Group EP. Outpatient antibi- otic use in Europe and association with resistance: a cross-national database study. Lancet. 2005; 365: 579-587.

6. Wang DY, Wardani RS, Singh K, et al. A survey on the management of acute rhinosinusitis among Asian physicians. Rhinology. 2011; 49: 264-271.

7. van Buchem FL, Knottnerus JA, Schrijnemaekers VJ, Peeters MF. Primarycare-based randomised placebo-controlled trial of antibiotic treatment in acute maxillary sinusitis. Lancet. 1997; 349: 683-687.

8. Young J, De Sutter A, Merenstein D, et al. Antibiotics for adults with clinically diagnosed acute rhinosinusitis: a meta-analysis of individual patient data. Lancet. 2008; 371: 908-914.

9. Hickner JM, Bartlett JG, Besser RE, et al Principles of appropriate antibiotic use for acute rhinosinusitis in adults: background.
Ann Emerg Med. 2001; 37: 703-710.

10. Upchurch J, Rosemore M, Tosiello R, Kowalsky S, Echols R. Randomized double-blind study comparing 7- and 10-day regimens of faropenem medoxomil with a 10-day cefuroxime axetil regimen for treatment of acute bacterial sinusitis. Otolaryngol Head Neck Surg. 2006; 135: 511-517.

11. Tellier G, Brunton SA, Nusrat $R$. Telithromycin for the treatment of acute bacterial maxillary sinusitis: a review of a new antibacterial agent. South Med J. 2005; 98: 863-868.

12. Gehanno P, Berche P, Hercot $O$, et al. [Efficiency of a four-day course of pristinamycin compared to a five-day course of cefuroxime axetil for acute bacterial maxillary sinusitis in adult outpatients]. Med Mal Infect. 2004; 34: 293-302. 
13. Buchanan PP, Stephens TA, Leroy B. A comparison of the efficacy of telithromycin versus cefuroxime axetil in the treatment of acute bacterial maxillary sinusitis. Am J Rhinol. 2003; 17: 369-377.

14. Siegert R, Berg O, Gehanno P, et al. Comparison of the efficacy and safety of faropenem daloxate and cefuroxime axetil for the treatment of acute bacterial maxillary sinusitis in adults. Eur Arch Otorhinolaryngol. 2003; 260: 186-194.

15. Siegert R, Gehanno P, Nikolaidis P, et al. A comparison of the safety and efficacy of moxifloxacin (BAY 12-8039) and cefuroxime axetil in the treatment of acute bacterial sinusitis in adults. The Sinusitis Study Group. Respir Med. 2000; 94: 337-344.

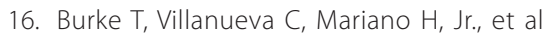
Comparison of moxifloxacin and cefuroxime axetil in the treatment of acute maxillary sinusitis. Sinusitis Infection Study Group. Clin Ther. 1999; 21: 1664-1677.

17. Henry DC, Sydnor A, Jr., Settipane GA, et al. Comparison of cefuroxime axetil and amoxicillin/clavulanate in the treatment of acute bacterial sinusitis. Clin Ther. 1999; 21: 1158-1170.

18. Gehanno P, Berche P. Sparfloxacin versus cefuroxime axetil in the treatment of acute purulent sinusitis. Sinusitis Study Group. J Antimicrob Chemother. 1996; 37 Suppl A: 105-114.

19. Kristo A, Uhari M, Luotonen J, Ilkko E, Koivunen P, Alho OP. Cefuroxime axetil versus placebo for children with acute respiratory infection and imaging evidence of sinusitis: a randomized, controlled trial. Acta Paediatrica. 2005; 94: 1208-1213.

20. Ferguson BJ, Guzzetta RV, Spector SL, Hadley JA. Efficacy and safety of oral telithromycin once daily for 5 days versus moxifloxacin once daily for 10 days in the treatment of acute bacterial rhinosinusitis. Otolaryngol Head Neck Surg. 2004; 131: 207-214.

21. Luterman M, Tellier G, Lasko B, Leroy B. Efficacy and tolerability of telithromycin for 5 or 10 days vs amoxicillin/clavulanic acid for 10 days in acute maxillary sinusitis. Ear Nose Throat J. 2003; 82: 576-86.

22. Roos K, Brunswig-Pitschner C, Kostrica R, et al. Efficacy and tolerability of once-daily therapy with telithromycin for 5 or 10 days for the treatment of acute maxillary sinusitis. Chemother. 2002; 48: 100-108.

23. Henry DC, Riffer E, Sokol WN, Chaudry NI, Swanson RN. Randomized double-blind study comparing 3- and 6-day regimens of azithromycin with a 10-day amoxicillin-clavulanate regimen for treatment of acute bacterial sinusitis. Antimicrob Agents Chemother. 2003; 47: 2770-2274.

24. Wald ER, Nash D, Eickhoff J. Effectiveness of amoxicillin/clavulanate potassium in the treatment of acute bacterial sinusitis in children. Pediatrics. 2009; 124: 9-15.

25. Seggev JS, Enrique RR, Brandon ML, Larsen LS, Van Tuyl RA, Rowinski CA. A combination of amoxicillin and clavulanate every 12 hours vs every 8 hours for treatment of acute bacterial maxillary sinusitis. Arch Otolaryngol Head Neck Surg. 1998; 124: 921-925.

26. Marple BF, Roberts CS, de Caprariis PJ, Reisman A. Onset of symptom resolution in adults with acute bacterial rhinosinusitis treated with a single dose of azithromycin extended release compared with 10 days of levofloxacin: a retrospective analysis of a randomized, double-blind, double-dummy trial. Clin Ther. 2007; 29: 2690-2698.

27. Poole M, Anon J, Paglia M, Xiang J, Khashab M, Kahn J. A trial of high-dose, short-course levofloxacin for the treatment of acute bacterial sinusitis. Otolaryngol Head Neck Surg. 2006; 134: 10-17.

28. Murray JJ, Emparanza P, Lesinskas E, Tawadrous M, Breen JD. Efficacy and safety of a novel, single-dose azithromycin microsphere formulation versus 10 days of levofloxacin for the treatment of acute bacterial sinusitis in adults. Otolaryngol Head Neck Surg. 2005; 133: 194-200.

29. Henry DC, Kapral D, Busman TA, Paris MM Cefdinir versus levofloxacin in patients with acute rhinosinusitis of presumed bacterial etiology: a multicenter, randomized, double-blind study. Clin Ther. 2004; 26: 20262033.

30. Lasko B, Lau CY, Saint-Pierre C, Reddington $J$, Martel A, Anstey RJ. Efficacy and safety of oral levofloxacin compared with clarithromycin in the treatment of acute sinusitis in adults: a multicentre, double-blind, randomized study. The Canadian Sinusitis Study Group. J Int Med Res. 1998; 26: 281-291.

31. Klossek JM, Siegert R, Nikolaidis P, Arvis P, Leberre MA, Sinusitis Study G. Comparison of the efficacy and safety of moxifloxacin and trovafloxacin for the treatment of acute, bacterial maxillary sinusitis in adults. J Laryngol Otol. 2003; 117: 43-51.

32. Clifford K, Huck W, Shan M, Tosiello R, Echols RM, Heyd A. Double-blind comparative trial of ciprofloxacin versus clarithromycin in the treatment of acute bacterial sinusitis. Sinusitis Infection Study Group. Ann Otol Rhinol Laryngol. 1999; 108: 360-367.

33. Murray JJ, Solomon E, McCluskey D, Zhang J, Palmer R, Notario G. Phase III, randomized, double-blind study of clarithromycin extended-release and immediate-release formulations in the treatment of adult patients with acute maxillary sinusitis. Clin Ther. 2000; 22: 1421-1432.

34. Wald ER, Chiponis D, Ledesma-Medina J. Comparative effectiveness of amoxicillin and amoxicillin-clavulanate potassium in acute paranasal sinus infections in children: a double-blind, placebo-controlled trial. Pediatrics. 1986; 77: 795-800.

35. Lindbaek M, Hjortdahl P, Johnsen UL. Randomised, double blind, placebo controlled trial of penicillin $V$ and amoxycillin in treatment of acute sinus infections in adults. BMJ. 1996; 313: 325-329.

36. Stalman W, van Essen GA, van der Graaf $Y$, de Melker RA. The end of antibiotic treatment in adults with acute sinusitis-like complaints in general practice? A placebo-controlled double-blind randomized doxycycline trial. Br J Gen Pract. 1997; 47: 794-799.

37. Hansen JG, Schmidt $H$, Grinsted $P$. Randomised, double blind, placebo controlled trial of penicillin $V$ in the treatment of acute maxillary sinusitis in adults in general practice. Scandinavian journal of primary health care. 2000 Mar;18(1):44-7.

38. 38 Varonen H, Kunnamo I, Savolainen S, et al. Treatment of acute rhinosinusitis diagnosed by clinical criteria or ultrasound in primary care. A placebo-controlled randomised trial. Scand J Prim Health Care. 2003; 21: 121-126.

39. Hadley JA, Mosges R, Desrosiers M, Haverstock D, van Veenhuyzen D, HermanGnjidic Z. Moxifloxacin five-day therapy versus placebo in acute bacterial rhinosinusitis. Laryngoscope. 2010; 120: 1057-1062.

40. Hansen FS, Hoffmans R, Georgalas C, Fokkens WJ. Complications of acute rhinosinusitis in The Netherlands. Fam Pract. 2012; 29: 147-153.

41. Babar-Craig H, Gupta Y, Lund VJ. British Rhinological Society audit of the role of antibiotics in complications of acute rhinosinusitis: a national prospective audit. Rhinology. 2010; 48: 344-347.

42. European Academy of Allergology and Clinical Immunology. European position paper on rhinosinusitis and nasal polyps. Rhinology Suppl 18. 2005: 1-87.

De-Yun Wang, MD, PhD

Department of Otolaryngology

National University of Singapore

National University Health System

1 E Kent Ridge Road

Singapore 119228

Tel: $+65-67725373$

Fax: +65-6775 3820

E-mail: entwdy@nus.edu.sg 